\title{
Estimating E-Race European Corn Borer (Lepidoptera: Crambidae) Adult Activity in Snap Bean Fields Based on Corn Planting Intensity and Their Activity in Corn in New York Agroecosystems
}

\author{
Rebecca A. Schmidt-Jeffris, ${ }^{1, *}$ Anders S. Huseth, ${ }^{2}$ and Brian A. Nault ${ }^{1}$ \\ 'Department of Entomology, Cornell University, New York State Agricultural Experiment Station, 630 W. North Street, Geneva, NY, \\ 14456 (schmidt-jeffris@cornell.edu; ban6@cornell.edu), Department of Entomology, Campus Box 7630, North Carolina State \\ University, Raleigh, NC, 27695 (ashuseth@ncsu.edu) and *Corresponding author, e-mail: schmidt-jeffris@cornell.edu
}

Received 29 February 2016; Accepted 2 June 2016

\begin{abstract}
European corn borer, Ostrinia nubilalis (Hübner), is a major pest of processing snap bean because larvae are contaminants in pods. The incidence of $O$. nubilalis-contaminated beans has become uncommon in New York, possibly because widespread adoption of Bt field corn has suppressed populations. Snap bean fields located where $B t$ corn has been intensively grown in space and time may be at lower risk for $O$. nubilalis than fields located where $B t$ corn is not common. To manage $O$. nubilalis infestation risk, growers determine insecticide application frequency in snap bean based on pheromone-trapping information in nearby sweet corn fields; adult activity is presumed equivalent in both crops. Our goal was to determine if corn planting intensity and adult activity in sweet corn could be used to estimate $O$. nubilalis populations in snap bean in New York in 2014-2015. Numbers of $O$ nubilalis adults captured in pheromone-baited traps located in snap bean fields where corn was and was not intensively grown were similar, suggesting that $O$. nubilalis does not respond to local levels of $B t$ corn in the landscape. Numbers of Ostrinia nubilalis captured in pheromone-baited traps placed by snap bean fields and proximal sweet corn fields were not related, indicating that snap bean growers should no longer make control decisions based on adult activity in sweet corn. Our results also suggest that the risk of O. nubilalis infestations in snap bean is low ( $~ 80 \%$ of the traps caught zero moths) and insecticide applications targeting this pest should be reduced or eliminated.
\end{abstract}

Key words: Ostrinia nubilalis, Phaseolus vulgaris, Zea mays, landscape ecology, pest monitoring

Snap bean (Phaseolus vulgaris L.) is an economically important crop grown for processing in the Great Lakes region of the United States. There are 56,000 ha of snap bean grown for processing in this region, generating $\$ 137$ million per year (NASS 2012). European corn borer, Ostrinia nubilalis (Hübner), is considered a major pest of snap bean. Ostrinia nubilalis has three distinct races that are differentiated by voltinism and sex pheromone (Roelofs et al. 1985). There is a bivoltine Erace (hereafter referred to as E-race) and separate univoltine and bivoltine Z-races (Roelofs et al. 1985). Among these races, the E-race has been more successful establishing on snap bean in New York (Eckenrode and Webb 1989). Ostrinia nubilalis overwinters as final instar, typically within corn (Zea mays L.) stalks and other field debris, and pupates in the spring (Hudon et al. 1989, Flood et al. 2005). Adults emerge and mate, and females lay their eggs on the foliage of corn or other crops (Hudon et al. 1989, Flood et al. 2005).

Snap bean is considered a low-preference host for O. nubilalis because oviposition rates are low (Dively and McCully 1979) and larval mortality is high (>90\%; Cranshaw and Radcliffe 1984, Webb et al. 1987, Eckenrode and Webb 1989). Larvae feed on snap bean foliage initially, but will bore into pods and stems (Dively and McCully 1979, Sanborn et al. 1982). Stem feeding can reduce plant health by limiting the movement of nutrients throughout the plant (Dively and McCully 1979), but this type of damage unlikely results in significant yield loss. The reason $O$. nubilalis is considered one of the most important pests of snap bean is because larvae feed inside pods, which contaminates the product when the beans are processed. Consequently, snap bean processors have implemented very low pod contamination thresholds for this pest (approximately one larvae per 1,000-4,000 pods; Dively and McCully 1979, Sanborn et al. 1982, Eckenrode and Webb 1989). Historically, O. nubilaliscontaminated snap bean pods have resulted in $>\$ 200,000$ in losses per processing company (Eckenrode et al. 1983).

To control O. nubilalis infestations in snap bean, growers typically apply one to two pyrethroid insecticides beginning at bloom or early 
pod formation (Flood and Wyman 2005). These applications are prophylactic; timing is based on the phenology of the crop, not pest levels in the field (Dively and McCully 1979, Sanborn et al. 1982). The number of applications is determined in part by the prior history of the field being infested by $O$. nubilalis and reports of adult male activity in the area. For example, snap bean processors and growers in New York will monitor moth activity from the New York State Integrated Pest Management Sweet Corn Pheromone Trapping Network (hereafter referred to as NYS IPM traps). Reports of moth activity are available online on a weekly basis during the growing season. However, NYS IPM traps are positioned adjacent to sweet corn fields for the purpose of monitoring pest activity in sweet corn, and this information may not accurately reflect $O$. nubilalis activity in snap bean fields. In addition, traps are widely spaced throughout the region where sweet corn is grown (one per county), so the distance between a snap bean field and the nearest NYS IPM trap may be considerable and could limit its utility in making management decisions. This is especially problematic because O. nubilalis does not disperse long distances, so information from the NYS IPM traps may be only locally applicable (Eckenrode et al. 1983).

Recently, the detection of $\mathrm{O}$. nubilalis-contaminated snap bean pods harvested from fields in central and western New York has been low to absent. The reason for this is unknown, but a potential explanation is the decline of O. nubilalis populations. Area-wide suppression of $O$. nubilalis is well-documented in other regions of the United States and has been attributed to increased acreage of $B t$ field corn varieties that kill a high proportion of larvae (Tabashnik 2010, Bohnenblust et al. 2014). In the United States, 76\% of field corn grown contains Bt (Fernandez-Cornejo et al. 2014). In landscapes dominated by annual production of $B t$ field corn, O. nubilalis populations might be very low (Hutchison et al. 2010). In such situations, alternative hosts for O. nubilalis (e.g., snap bean) may especially benefit from high concentrations of $B t$ field corn in the landscape, reducing the need to protect the snap bean crop with prophylactic insecticide applications.

The objectives of this study were to determine 1) the relationship between dominance of field corn plantings in the landscape over time and E-race O. nubilalis adult densities, and 2) whether a positive relationship exists between numbers of E-race O. nubilalis adults captured in the NYS IPM traps (adjacent to sweet corn fields) and those captured in our identical traps placed adjacent to snap bean fields. We hypothesized that fewer E-race O. nubilalis adults would be captured near snap bean fields located within field corndominated landscapes, and that there would be no relationship between numbers of E-race adults caught in traps located in sweet corn and snap bean fields. Prior studies have examined the relationship between the dominance of corn or cropland in the landscape and O. nubilalis damage to corn (O'Rourke et al. 2011, Bohnenblust et al. 2014). However, these studies only examined the dominance of corn in the year of sampling; in contrast, we examined the effects of both spatial and temporal corn planting intensity on O. nubilalis adult densities in snap bean, a non-preferred host.

\section{Materials and Methods}

\section{Snap Bean Field Sites and Landscape Analysis}

A snap bean processor in New York provided the locations of all snap bean fields contracted in 2014 and 2015. In New York, snap bean plantings are staggered from May to late July. Fields selected in our study were planted from 30 May to 25 July $2014(n=30$ fields) and 1 May to 25 July 2015 ( $n=40$ fields). The mean ( \pm SE) field size was $13.1( \pm 1.1)$ ha, and the most common cultivar was 'Huntington' (64\%), followed by 'BA1001' (19\%). Ostrinia nubilalis was targeted with foliar insecticide applications, primarily bifenthrin (92\% of applications), and fields received a mean of 1.4 $( \pm 0.1)$ insecticide applications.

To test our hypothesis that fewer E-race O. nubilalis would be captured in snap bean fields in areas where Bt corn was intensively grown compared with areas where it was not, snap bean fields needed to be binned into these two categories among the hundreds of snap bean fields planted in New York. The dominance of corn in the area surrounding each snap bean field was quantified using a method adapted from Huseth et al. (2015b). Similar to the national trend, the majority of field corn planted in New York is estimated to include at least one of the $B t$ proteins that targets O. nubilalis. Data describing the cropping history of the landscape were obtained from National Agricultural Statistics Service-Cropland Data Layer (CDL; US Department of Agriculture 2015). The data layer is a remotely sensed, categorical description of agricultural, urban, and natural land use at a $30 \mathrm{~m}$ pixel resolution. Corn crop history was determined from all available years prior to study year 2014 (20082013) and 2015 (2008-2014); pixels planted to field corn are given a value of " 1 " in the CDL. Annual CDL layers were each reclassified into a binary layer (corn or not corn), then sequentially summed to determine the number of years each pixel within the raster had been planted to corn (QGIS 2015). A $1000 \mathrm{~m}$ buffer was placed around each point representing a snap bean field because this would presumably encompass the maximum dispersal distance for O. nubilalis adults and has previously been used to examine the effect of landscape on O. nubilalis (O'Rourke et al. 2011). For the area within each buffer, the corn dominance metric (CDM) was calculated:

$$
C D M=\frac{\sum_{i=1}^{j} T_{i}}{{\text { Corn } \text { area }_{i}}}
$$

where $i$ is a year prior to $O$. nubilalis trapping and $j$ is every consecutive year prior to $i . T_{i}$ is the total area (number of pixels or 30 by $30-\mathrm{m}$ areas of land) of corn in the landscape for each of the years prior to O. nubilalis trapping. This was summed across all years prior to O. nubilalis trapping (starting with 2008, the first year the data were available). Corn area $_{i}$ is the total area (number of pixels) planted to corn in any of the six (2014) or seven (2015) years prior to O. nubilalis trapping. If a pixel was planted to corn in at least one of these years (2008-2014 or 2008-2015), it was counted as " 1 "; if a pixel was never planted to corn, it was counted as " 0 ".

The mean CDM for all snap bean fields and its standard deviation (SD) were calculated. Fields with a CDM $>1$ SD or $<1$ SD from the mean were considered "high CDM" or "low CDM" fields, respectively (Supp. Fig. 1 [online only]). From this pool of "high" and "low" CDM snap bean fields, 16 high and 14 low sites were selected for trapping in 2014 and 20 high and 20 low sites were selected for trapping in 2015 (Fig. 1). Within the pool of "high" and "low" CDM fields, site locations were selected at random, with the caveat that the $1000 \mathrm{~m}$ buffer of the sites could not overlap.

\section{E-race Ostrinia nubilalis Adult Trapping Snap Bean}

At each snap bean field site, E-race O. nubilalis adult activity was monitored using a nylon mesh Heliothis trap (Scentry Biologicals, Inc., Billings, MN). Traps were installed on posts in grassy margins near each snap bean field, with the trap entrance $\sim 0.3 \mathrm{~m}$ above the top of the foliage. Each trap was baited with O. nubilalis E-race pheromone lure (European Corn Borer NY pheromone lure, Scentry Biologicals Inc., Billings, MN). The number of male moths captured in each trap was considered a proxy for estimating the size of the $O$. 


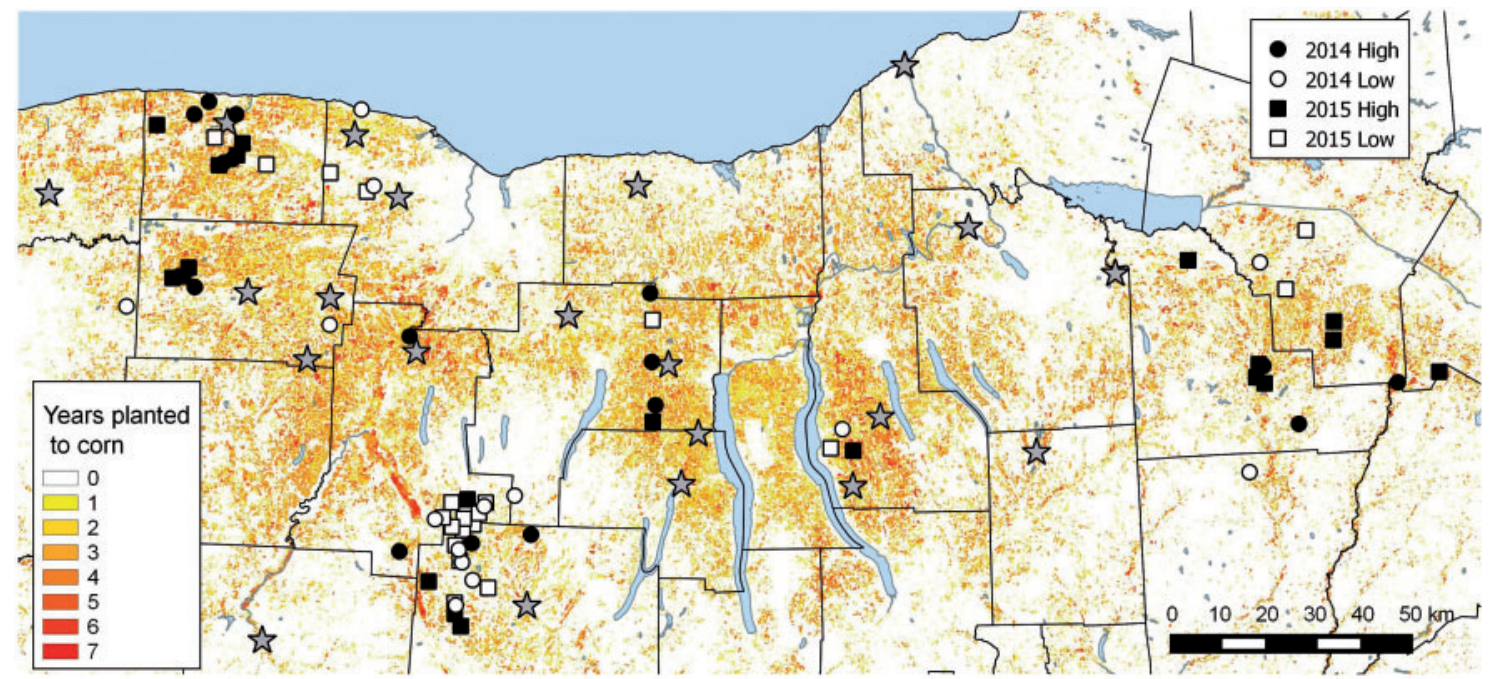

Fig. 1. Locations of snap bean fields (2014: circles, 2015: squares) and NYS IPM sweet corn trapping network locations (stars) that were monitored for O. nubilalis adults ( $E$ race). Snap bean fields with filled symbols (black) were located in landscapes planted frequently with corn (High CDM), whereas snap bean fields with open symbols (white) were located in landscapes that were not often planted with corn (Low CDM). CDM was a measure of the frequency that land was planted with corn over 6-7 years. Map shading indicates the number of years an area was planted to corn.

nubilalis population in the immediate area (Laurent and Frérot 2007).

Trap installation date was determined by the phenology of the snap bean crop. Snap beans are most attractive to O. nubilalis during flowering (Hutchison et al. 2004), which occurs $\sim 35-45 \mathrm{~d}$ after planting. We targeted this period by installing traps $\sim 30 \mathrm{~d}$ after planting. Traps were inspected for $O$. nubilalis adults once weekly for $3 \mathrm{wk}$; pheromone lures were changed during each trap inspection to maximize the probability of luring adults to the trap. Cumulative total number of adults per trap was the dependent variable used for comparing high and low CDM sites.

\section{Sweet Corn}

NYS IPM traps used a similar methodology as our trapping in snap bean fields (described previously), but lures were changed every 2 wk and traps were monitored throughout the sweet corn growing season (mid-May to late September). Numbers of E-race O. nubilalis adults captured in NYS IPM traps were obtained from publicly available reports (http://sweetcorn.nysipm.cornell.edu/). As mentioned previously, numbers of male moths captured in traps by sweet corn fields were considered a proxy for estimating densities of O. nubilalis in the immediate area.

For both years, NYS IPM traps were paired with the nearest trap located in a snap bean field. A criterion for selecting trap pairings was that traps must be $<20 \mathrm{~km}$ apart. In total, 10 pairs of traps were selected each year. The mean $( \pm \mathrm{SE})$ distance between sweet corn and snap bean traps was 9.1 ( \pm 0.9$) \mathrm{km}$. For each NYS IPM trap, only data collected during the same period as the period sampled in the trap located in the paired snap bean field were used. The mean number of E-race O. nubilalis adults captured per trap per week was considered the dependent variable and used to compare densities between each sweet corn-snap bean trap pair.

\section{Data Analysis}

All analyses were performed using generalized linear models (PROC GLIMMIX, SAS Institute, Cary, NC). To ensure that there was no confounding effect of installation date between high and low CDMdesignated sites, the relationship between CDM group and trap installation date was examined for an association, specifying a binary distribution with CDM group as the response variable. There was no relationship between CDM group and trap installation date in either year of the study (2014: $F=1.44 ; \mathrm{df}=1,28 ; P=0.2401$; 2015: $F=3.39, \mathrm{df}=1,38, P=0.0734)$. We also confirmed that the number of pesticide applications in snap bean fields (count data, negative binomial distribution) did not differ between the 'high' and 'low' CDM groups (2014: $F=0.19 ; \mathrm{df}=1,28 ; P=0.6622 ; 2015$ : $F=2.41, \mathrm{df}=1,38, P=0.1287)$.

Percentage of land area in cultivated crops was calculated for the year of sampling within the buffer of each trap site. This was done by using the CDL for the appropriate year (2014 or 2015) to classify each pixel within a buffer as agricultural or non-agricultural land. To confirm that percentage agricultural land was not confounded with CDM, this percentage was compared in the 'high' and 'low' CDM groups for both years (specifying a binomial distribution for proportion data). No relationship was found in either year (2014: $F=0.36$; df $=1,28$; $P=0.5523 ; 2015: F=0.67 ; \mathrm{df}=1,38 ; P=0.4188)$. We also examined the relationship between percentage of agricultural land and numbers of E-race O. nubilalis adults captured in snap bean fields (disregarding CDM). Here, a negative binomial distribution was used for count data.

Numbers of E-race O. nubilalis adults captured from NYS IPM traps and in snap bean fields were examined for an association (count data, negative binomial distribution). Mean numbers of $O$. nubilalis adults captured per trap per week from all NYS IPM sweet corn traps also were compared with those in all snap bean fields during the same period of each season.

\section{Results and Discussion}

E-race O. nubilalis adult activity was similar near snap bean fields that were located in areas where field corn dominated in space and time (high CDM) and locations where field corn was grown less intensively (low CDM; Fig. 2). These results support those reported in a similar study in New York in which levels of O. nubilalis damage in corn fields were similar across landscapes that varied in percentage of area planted with corn (0-50\%; O'Rourke et al. 2011). In that study, the absence of differences in O. nubilalis damage among these corn fields was attributed to the availability of suitable hosts 


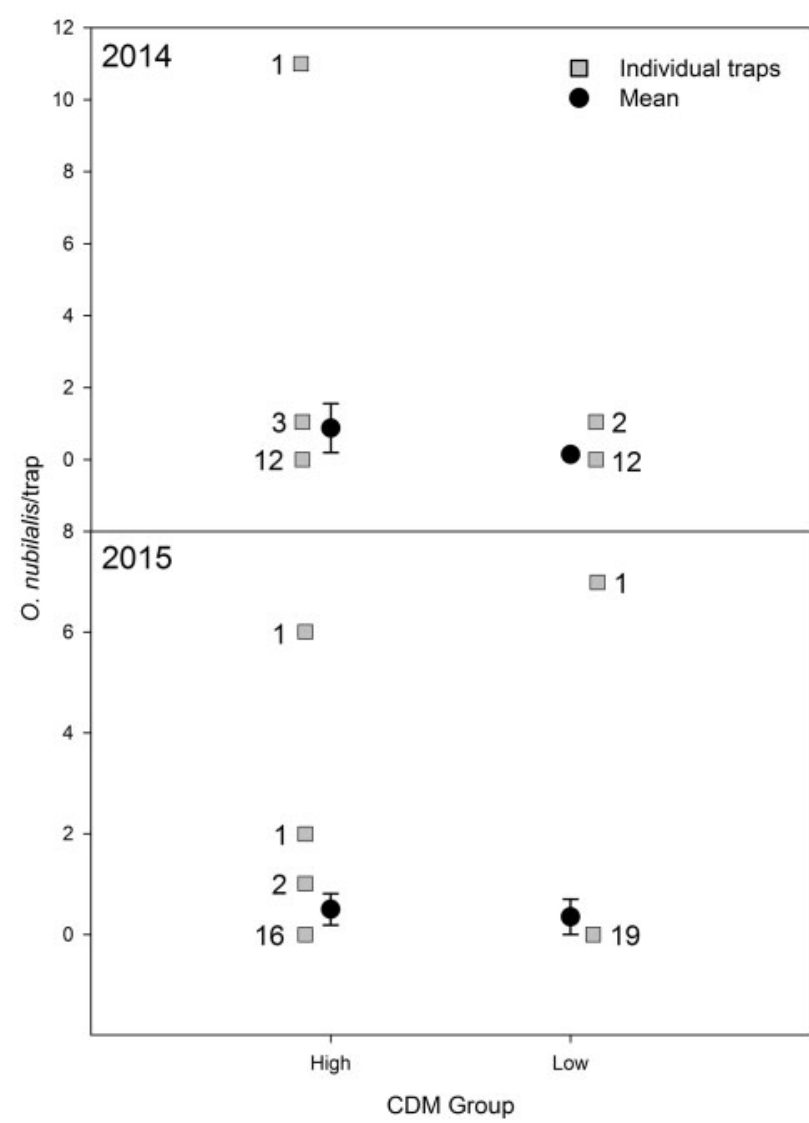

Fig. 2. Mean total number $( \pm \mathrm{SE}$ ) of $O$. nubilalis adults ( $E$ race) captured in pheromone-baited traps located in snap bean fields designated in high or low CDM groups for (a) $2014(F=2.45 ; \mathrm{df}=1,28 ; P=0.1286)$ and (b) 2015 $(F=0.07 ; \mathrm{df}=1,38 ; P=0.7862)$. Moths were sampled weekly from traps over 3 wk. Numbers adjacent to individual trap catch squares indicate the frequency of the observation.

in landscapes with lower percentages of corn for O. nubilalis to persist (O'Rourke et al. 2011). However, an additional explanation may be that the presence of O. nubilalis' preferred host (corn) attracts females into this landscape, but the presence of the $B t$ trait in most corn fields serves as a dead-end host, thereby reducing its overall population size, causing a net neutral effect of corn. No relationship between regional $B t$ corn adoption rates and $O$. nubilalis damage has been reported, despite the known relationship between increased $B t$ corn adoption through time and reduced O. nubilalis populations (Hutchison et al. 2010, Bohnenblust et al. 2014).

There was no relationship between percent agriculture in the landscape and numbers of E-race O. nubilalis captured in traps in snap bean fields (2014: $F=1.91 ; \mathrm{df}=1,28 ; P=0.1779 ; 2015$ : $F=0.21 ; \mathrm{df}=1,38 ; P=0.6461)$. These results were similar to those reported by O'Rourke et al. (2011) and Bohnenblust et al. (2014), who did not observe a relationship between numbers of O. nubilalis adults captured in pheromone traps located in areas differing in percent agriculture in the landscape. Ostrinia nubilalis may not respond to agriculture in the landscape because there is a wide availability of alternative hosts (O'Rourke et al. 2010, 2011).

Overall, the majority of traps in snap bean fields in both years of our study did not catch any E-race O. nubilalis ( $80 \%$ in $2014,88 \%$ in 2015; Fig. 2). This result indicates that moth populations were extremely low in sampled landscapes. Moreover, these results support anecdotal evidence provided by snap bean processing industry

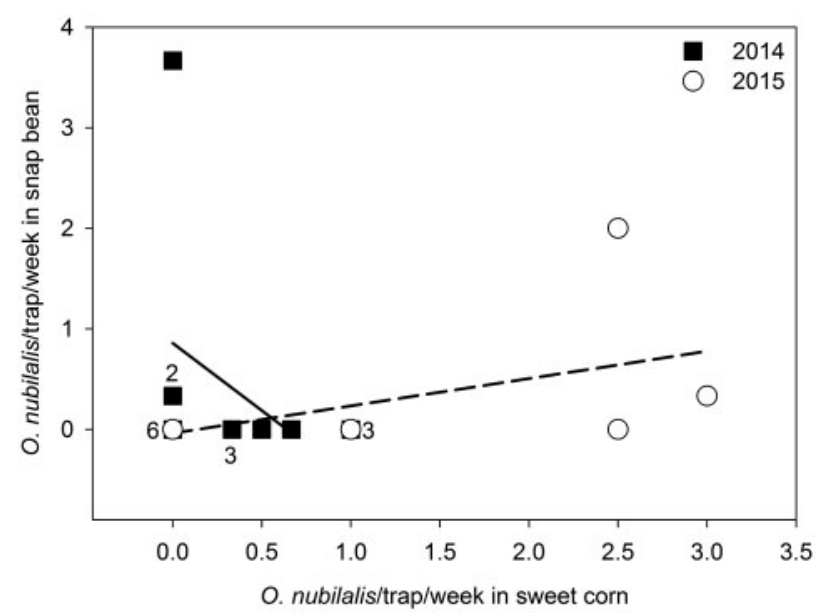

Fig. 3. Comparison of numbers of $O$. nubilalis ( $E$ race) adults caught in NYS IPM traps by sweet corn fields and those captured in traps by snap bean fields in New York. Trend lines for 2014 (solid) and 2015 (dashed) are shown. Numbers adjacent to points indicated the number of trap pairs represented by that point (otherwise $n=1$ ).

experts that $O$. nubilalis has become a rare problem in central and western NY. Indeed, our study likely overestimates the threat of infestation, as the presence of the very few captured male moths does not guarantee that female moths will lay eggs in nearby fields or that the offspring will survive in the snap bean crop.

There was no relationship between numbers of E-race O. nubilalis adults captured in the NYS IPM sweet corn traps and those captured in the snap bean traps (2014: $F=0.01, \mathrm{df}=1,8, P=0.9063 ; 2015$ : $F=1.38, \mathrm{df}=1,8, P=0.2743$; Fig. 3 ). This is in contrast to previous work that has shown positive relationships between numbers of $O$. nubilalis adults in pheromone-baited traps and O. nubilalis larval damage levels in sweet corn (Bohnenblust et al. 2014). However, their study trapped O. nubilalis adults in sweet corn fields to predict damage in nearby field corn fields, which is a much more preferable host than snap bean. The mean numbers of adults captured per week in the NYS IPM trapping network were significantly higher than those in snap bean fields in both years (2014: $F=14.89, \mathrm{df}=1,52, P=0.0003$; 2015: $F=32.11, \mathrm{df}=1,63, P<0.0001$; Fig. 4). Because pheromone lures, traps, and trap placement along field edges were identical in sweet corn and snap bean fields, the low numbers of moths captured in traps by snap bean fields compared with sweet corn fields were not a reflection of differences in methodology. Instead, these results indicated that information from the NYS IPM trapping network was not helpful for informing management decisions in snap bean. Currently, growers who use information from the NYS IPM trapping network and determine that a second insecticide application is needed in snap bean may overestimate their risk of O. nubilalis contamination in those snap bean fields. This assessment would result in the over-application of insecticides, increasing the cost to the grower and the environmental footprint of the management program.

Our results suggest that processing snap bean fields in New York are at low risk for O. nubilalis infestations. Consequently, snap bean growers and processors should re-evaluate their current approach of using one to two prophylactic applications of pyrethroids to protect their crop from $O$. nubilalis. New insecticides are now available that have long residual activity for insect control on vegetable crops. For example, Huseth et al. (2015a) showed that a single application of a diamide insecticide, like chlorantraniliprole or cyantraniliprole, provided an equivalent level of O. nubilalis control on snap bean as two applications of a pyrethroid insecticide. 


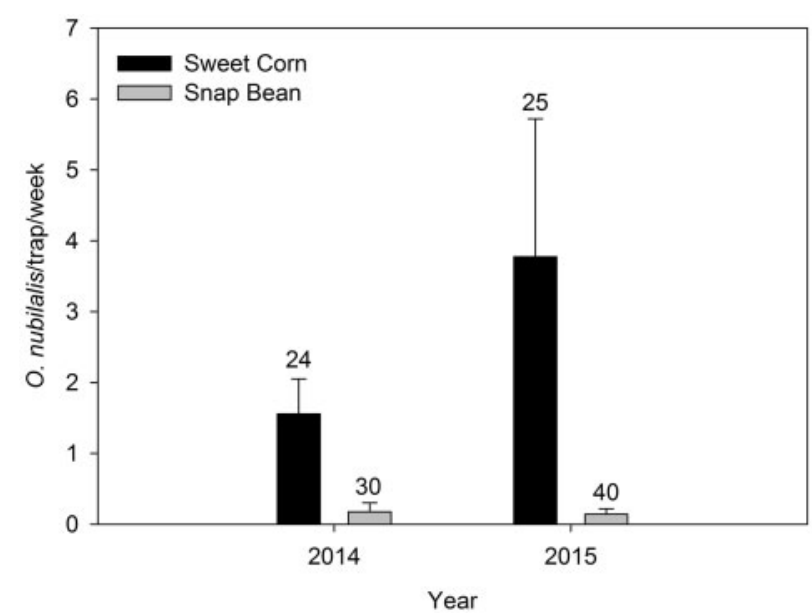

Fig. 4. Mean number $( \pm \mathrm{SE}$ ) of $O$. nubilalis adults ( $E$ race) captured per trap per week in the NYS IPM traps positioned by sweet corn fields and in traps located in snap bean fields. Numbers above the bars indicate sample size $(n)$.

The low numbers of E-race O. nubilalis moths captured in most traps (snap bean and sweet corn) suggest that $B t$ field corn in New York may have had an area-wide suppression of this pest similar to the Midwest (Hutchison et al. 2010). However, E-race O. nubilalis adults continue to be captured in relatively high numbers (seasonal mean of 30 moths/trap/week; $>200$ moths in a single trap in one week in 2015) in certain locations in the eastern United States (PA and NY), but it is not known why high moth densities persist in some locations. Perhaps, the localized pockets of high O. nubilalis activity are associated with concentrations of a host in which it thrives. For example, there are areas where processing (non Bt) sweet corn is concentrated in New York. Repeated plantings of non$B t$ varieties within a landscape may provide both an attractive oviposition site for O. nubilalis (preferred corn host) and simultaneously allow the population to persist (non-Bt).

\section{Acknowledgments}

We thank Abby Seaman and Marion Zuefle for the use of the New York State Integrated Pest Management Sweet Corn Pheromone Trap Network reports. We also thank Dan Olmstead for providing QGIS support. We thank the cooperating growers who allowed us to sample their fields. We gratefully acknowledge the technical support of Molly Cappiello, Andrew Ritter, and McKenzie Schessl. This research was supported in part by grants from the New York State Vegetable Research Council and USDA SCRI NIFA Grant \#2012-51181-20001, "Building Market Foundations for Sustainable Vegetable Production and Processing”.

\section{References Cited}

Bohnenblust, E. W., J. A. Breining, J. A. Shaffer, S. J. Fleischer, G. W. Roth, and J. F. Tooker. 2014. Current European corn borer, Ostrinia nubilalis, injury levels in the northeastern United States and the value of $B t$ field corn. Pest Manag. Sci. 70: 1711-1719.

Cranshaw, W. S., and E. B. Radcliffe. 1984. Influence of cultivar and plant age on European corn borer (Lepidoptera: Pyralidae) infestation in snap beans. J. Econ. Entomol. 77: 374-376.

Dively, G. P., and J. E. McCully II. 1979. Nature and distribution of European 'corn borer feeding injury on snap beans. J. Econ. Entomol. 72: $152-154$.
Eckenrode, C. J., and D. R. Webb. 1989. Establishment of various European corn borer (Lepidoptera: Pyralidae) races on selected cultivars of snap beans. J. Econ. Entomol. 82: 1169-1173.

Eckenrode, C. J., P. S. Robbins, and J. T. Andaloro. 1983. Variations in flight patterns of European corn borer (Lepidoptera: Pyralidae) in New York. Environ. Entomol. 12: 393-396.

Fernandez-Cornejo, J., S. Wechsler, M. Livingston, and L. Mitchell. 2014. Genetically engineered crops in the United States. ERR-162 U.S. Department of Agriculture Economic Research Service.

Flood, B. R., and J. A. Wyman. 2005. Beans, pp. 64-81. In R. Fosternd B. R. Flood (eds.), Vegetable Insect Management. Miester Media Worldwide, Willoughby, OH.

Flood, B. R., W. D. Hutchison, and S. Pataky. 2005. Sweet corn, pp. 38-63. In R. Fosternd B. R. Flood (eds.), Vegetable Insect Management. Miester Media Worldwide, Willoughby, $\mathrm{OH}$.

Hudon, M., E. J. LeRoux, and D. G. Harcourt. 1989. Seventy years of European corn borer (Ostrinia nubilalis) research in North America. In G. E. Russell (ed.), Agricultural Zoology Reviews, vol. 3. Intercept, Wimborne, United Kingdom.

Huseth, A. S., R. L. Groves, S. A. Chapman, and B. A. Nault. 2015a. Evaluation of diamide insecticdes co-applied with other agrochemicals at various times to manage Ostrinia nubilalis in processing snap bean. Pest Manag. Sci. 71: 1649-1656.

Huseth, A. S., J. D. Petersen, K. Poveda, Z. Szendrei, B. A. Nault, G. G. Kennedy, and R. L. Groves. 2015b. Spatial and temporal potato intensification drives insecticide resistance in the specialist herbivore, Leptinotarsa decemlineata. PLoS ONE 10: e0127576.

12. Hutchison, W. D., B. Flood, and J. A. Wyman. 2004. Advances in United States sweet corn and snap bean insect pest management, pp. 247-78. In A. R. Horowitznd I. Ishaaya (eds.), Insect Pest Management: Field and Protected Crops. Springer-Verlag, Berlin, Germany.

Hutchison, W. D., E. C. Burkness, P. D. Mitchell, R. D. Moon, T. W. Leslie, S. J. Fleischer, M. Abrahamson, K. L. Hamilton, K. L. Steffey, M. E. Gray, et al 2010. Areawide suppression of European corn borer with Bt maize reaps savings to non-Bt maize growers. Science 330: 222-225.

Laurent, P., and B. Frérot. 2007. Monitoring of European corn borer with pheromone-baited traps: review of trapping system basics and remaining problems. J. Econ. Entomol. 100: 1797-1807.

NASS 2012. Processing snap bean production and acreage survey data. Quick Stats.

O’Rourke, M. E., T. W. Sappington, and S. J. Fleischer. 2010. Managing resistance to Bt crops in a genetically variable insect herbivore, Ostrinia nubilalis. Ecol. Appl. 20: 1228-1236.

O'Rourke, M. E., K. Rienzo-Stack, and A. G. Power. 2011. A multi-scale, landscape approach to predicting insect populations in agroecosystems. Ecol. Appl. 21: 1782-1791.

QGIS 2015. QGIS Desktop Geographic Information System User Guide. Open Source Geospatial Foundation Project, Version 2.8.2.

Roelofs, W. L., J. W. Du, X. H. Tang, P. S. Robbins, and C. J. Eckenrode. 1985. Three European borer populations in New York based on sex pheromones and voltinism. J. Chem. Ecol. 11: 829-836.

Sanborn, S. M., J. A. Wyman, and R. K. Chapman. 1982. Studies on the European corn borer in relation to its management on snap beans. J. Econ. Entomol. 75: 551-555.

Tabashnik, B. E. 2010. Communal benefit of transgenic corn. Science 330: 189-190.

US Department of Agriculture 2015. National Agriculture Statistics Service Spatial Analysis Research Section. Cropland Data Layer. (http://www.nass. usda.gov/research/Cropland/SARS1a.htm)

Webb, D. R., C. J. Eckenrode, and M. H. Dickson. 1987. Variation among green and wax beans in survival of larvae of a bivoltine- $E$ race of the European corn borer (Lepidoptera: Pyralidae). J. Econ. Entomol. 80: 521-524. 